\title{
In Vitro Assessment of Lactic Acid Bacteria Against Klebsiella pneumoniae., Isolated from Milk Sample
}

\author{
Krishnakumar B. ${ }^{1}$, Kavinkumar S. ${ }^{2}$ \\ Department of Microbiology Dr. N.G.P. Arts and Science College (Autonomous) Approved by Government of Tamil Nadu \& \\ Affiliated to Bharathiar University Re-accredited by NAAC with "A" Grade | DST-FIST | DBT-Star College \\ Kalapatti Road, Coimbatore, India - 641048.
}

\begin{abstract}
Mastitis is the most common and costly production disorder of dairy cattle. In the United States, approximately $\mathbf{4 0 \%}$ of clinical mastitis cases from which a pathogen is isolated are attributed to gram -negative organisms (Erskine et al., 1991). The most common Received February 28, 2006. Accepted March 31, 2006. 1 Corresponding author: rz26@cornell.edu 3425 gramnegative causes of clinical mastitis are coliform bacteria, specifically Escherichia coli and Klebsiella spp. (Smith et al., 1985; Erskine et al., 1991; Todhunter et al., 1991). Considering the damage caused by infections, and the poor response of Klebsiella mastitis to treatment, prevention is of paramount importance in control of Klebsiella mastitis.
\end{abstract}

The primary source of Klebsiella spp. in the cows' environment is organic bedding. Outbreaks of Klebsiella are commonly associated with sawdust bedding (National Mastitis Council, 1999). The antimicrobial effect of lactobacilli is primarily linked to the production of organic acids, such as lactic acid, acetic acid, propionic acid, and sometimes hydrogen peroxide, bacteriocins, and antimicrobial peptides (AMPs) with a variable range of action (CortesZavaleta et al. 2014; Gemechu 2015). A combination therapy, including probiotic and antibiotic may offer better antimicrobial activity and lessen the dose of antibiotic required. As LAB enjoy the 'generally recognized as safe' (GRAS) status, their metabolites have captivated substantial interest as natural drugs in recent years (Reis et al., 2012). In this study based on the information provided by the researchers the supernatant of the lactic acid bacterial strains were used in different concentrations to assessing the growth of Klebsiella pneumoniae., causing cow mastitis which has been isolated from the cow farm house. The supernatant of lactic acid bacteria which consist of several organic acids and some metabolites in it. That was treated with one of the important human and cattle pathogen Klebsiella pneumoniae, with the three different concentrations. And this current study was successfully comes with the expected inhibitory effect to the $K$. pneumoniae.,

Keywords:- Anti-Bacterial Activity, Cow Mastitis, Organic Acid, Supernatant.

\section{INTRODUCTION}

Mastitis is the most common and costly production disorder of dairy cattle and can manifest as subclinical infection or as clinical disease. In the United States, approximately $40 \%$ of clinical mastitis cases from which a pathogen is isolated are attributed to gram -negative organisms (Erskine et al., 1991). The most common Received February 28, 2006. Accepted March 31, 2006. 1 Corresponding author: rz26@cornell.edu 3425 gramnegative causes of clinical mastitis are coliform bacteria, specifically Escherichia coli and Klebsiella spp. (Smith et al., 1985; Erskine et al., 1991; Todhunter et al., 1991). Klebsiella pneumoniae is by far the most common Klebsiella species infecting animals (Brisse and Duijkeren, 2005). It is also the most common Klebsiella species to cause mastitis (Erskine et al., 2002b; Roberson et al., 2004). Losses due to Klebsiella mastitis are much higher than losses due to E. coli mastitis in terms of milk production and survival (Erskine et al., 2002a; Gro"hn et al., 2004). Klebsiella infections are less likely to respond to treatment and last significantly longer than $E$. coli infections (Smith et al., 1985; Roberson et al., 2004). The ratio of Klebsiella mastitis incidence to E. coli mastitis incidence varies from 1:10 to 1:1 across studies (Barkema et al., 1998; Roberson et al., 2004)

Considering the damage caused by infections, and the poor response of Klebsiella mastitis to treatment, prevention is of paramount importance in control of Klebsiella mastitis.

The primary source of Klebsiella spp. in the cows' environment is organic bedding. Outbreaks of Klebsiella are commonly associated with sawdust bedding (National Mastitis Council, 1999). Klebsiella can be present in living wood (Bagley et al., 1978) and fresh sawdust bedding can be a source of Klebsiella mastitis (Newman and Kowalski, 1973; Hogan et al., 1989). Other organic bedding materials, such as recycled newspaper and straw also support growth of Klebsiella (Hogan et al., 1990). Inorganic materials such as crushed limestone and sand are least likely to harbor Klebsiella (Hogan et al., 1989). Rates of teat-end contamination and clinical mastitis have been correlated to bacterial loads in bedding (Hogan et al., 1989; Zdanowicz et al., 2004), and use of inorganic bedding is recommended as an effective means of environmental sanitation and mastitis prevention (National Mastitis Council, 1999). 
The antimicrobial effect of lactobacilli is primarily linked to the production of organic acids, such as lactic acid, acetic acid, propionic acid, and sometimes hydrogen peroxide, bacteriocins, and antimicrobial peptides (AMPs) with a variable range of action (CortesZavaleta et al. 2014; Gemechu 2015). Strains of lactobacilli can produce organic acids through hetero fermentative pathways. These acids may perhaps interact with the cell membrane and induce intracellular acidification and protein denaturation. The antibacterial effect of lactic acid is probably due to the physiological and morphological changes induced in the bacterial cytoplasmic membrane, resulting in leakage of cytoplasmic contents (Wang et al., 2015). Beneficial effects of lactobacilli, including inhibition of Gram-positive and Gram-negative pathogenic and spoilage bacteria have been reported by many researchers (Song et al. 2014; Zhu et al., 2014). The therapeutic role of lactobacilli in controlling the infections caused by Pseudomonas aeruginosa, Staphylococcus aureus and Salmonella spp., has been reported. Combined action of Lactobacillus and antibiotic(s) has been shown to be successful in the management of Helicobacter pylori infection (Homan and Orel 2015; Safavi et al., 2016). A combination therapy, including probiotic and antibiotic may offer better antimicrobial activity and lessen the dose of antibiotic required. Further, it may also help in replenishment of the intestinal flora thereby providing benefit to the host and abating the side effects of antibiotics (Aminnezhad et al., 2015). The antagonistic activity of these microorganisms and/or their extracellular antibacterial agents (cellfree supernatants) also offers valuable prospects for their application in food preservation (Kecerova et al., 2004), as feed supplements, or in veterinary medicine (CortesZavaleta et al., 2014). As LAB enjoy the 'generally recognized as safe' (GRAS) status, their metabolites have captivated substantial interest as natural drugs in recent years (Reis et al., 2012). Lactic acid bacteria (LAB) can also be found in various habitats including in foods and drinks of plant and animal origins. Fermented foods and drinks are particularly rich in their content of LAB. LAB species of practical importance are usually nonpathogenic and safe, at least in healthy and immuno- competent people. Several reports have indicated that the shelflife of foods can be extended by LAB or LAB metabolites ( Abee T et al., 1995). Food safety is enhanced because of the inhibitory actions of LAB on common food-borne pathogens such as Escherichia coli O157::H7, Salmonella spp., and Listeria monocytogenes., Inhibition of food- borne pathogens by LAB can be mediated by competi- tive exclusion or production of organic acids and anti- microbial products such as hydrogen peroxide and antimicrobial peptides (e.g., bacteriocins). These products can be produced by some LAB and secreted when grown in appropriate broth medium. Either live LAB or their metabolic products can be used (O’Shea EF et al.,2013).

In this study based on the information provided by the researchers the supernatant of the lactic acid bacterial strains were used in different concentrations to assessing the growth of Klebsiella pneumoniae, causing cow mastitis which has been isolated from the cow farm house.

\section{MATERIALS AND METHODS}

\section{$>$ Isolation and Identification of Klebsiella pneumoniae., The milk sample was collected in screw cap tubes from the form house of cow where it has the high possibilities of Klebsiella contaminations. And transferred to the laboratory and kept in refrigerator under $4^{\circ} \mathrm{C}$ until the process begins.}

Culture Technique The milk sample was taken and serially diluted with sterile water for 10fold dilutions. And final three dilutions were taken and plated in nutrient agar plates. And incubated at $37^{\circ} \mathrm{C}$ for 24 hours. After incubation period the plates were observed for the growth of the colonies. After the colony appearances it was further tested for the isolation of particular isolates.

Gram staining Colonies with various morphological and cultural characteristics were picked and performed with gram staining to identify the different group of bacteria. And some of the gram negative isolates were identified and further tested.

Capsule staining Klebsiella will have the unique property to show clear zone around the organisms under the microscopic view. The selected gram negative isolates were stained with capsule staining to see the clear zone around the organisms because of the polysaccharides presence of the Klebsiella sp.,

Motility Test Selected gram negative isolates were further tested for motility with Hanging drop technique and SIM agar technique. Klebsiella normally non motile organism so that this test will give you the partial confirmation on the isolation of klebsiella sp.,

Biochemical Test The more preferred technique to identify the gram negative bacteria at the genus level. There are number of biochemical tests which gives the clear idea about the differentiation of gram negative bacteria. Here the gram negative and non-motile organisms were tested with IMViC test. Which includes indole, methyl red, voges proskauer, citrate utilization test. Klebsiella will have the negative results for the indole and methyl red tests. And having the positive results with the voges proskauer and citrate utilization tests. The selected isolates were inoculated in appropriate broth medium for the IMViC test and incubated at $37^{\circ} \mathrm{C}$ for 24 hours and checked for the observation of results by adding reagent solutions. Voges proskauer alone having 48hours incubation period.

Enzymatic Reactions This test can be done for the identification of whether any enzymatic reactions are involved or not.

Catalase Test The selected isolates were treated with hydrogen peroxide to see whether any effervescences are seen or not. 
Oxidase Test The selected isolates were kept on the oxidase disc to see whether any colour changes was occur or not.

MALDI-TOF analysis. Currently microorganisms are best identified using 16S rRNA and 18S rRNA gene sequencing. However, in recent years matrix assisted laser desorption ionization-time of flight mass spectrometry (MALDI-TOF MS) has emerged as a potential tool for microbial identification and diagnosis. During the MALDITOF MS process, microbes are identified using either intact cells or cell extracts. So that as a final step of the identification of the test isolates were given to the MALDITOF analysis in Microbiological laboratory, R.S.Puram, Coimbatore- 02 .

Isolation and identification of lactic acid bacteria (LAB) Capsules of lactic acid bacteria were bought from the near by medical shop and processed for the cultivation of LAB. The capsule consist of dry powder of lactic acid bacteria in it.

Culture Technique The dry powder of LAB was serially diluted with sterile water for 10 fold dilutions. And final three dilutions were taken and plated in nutrient agar plates and incubated at $37^{\circ} \mathrm{C}$ for 24 hours. After incubation period the plates were observed for the appearance of the colonies. And there should be a pure culture in culture plate because of the sample used here is a well known one.

Gram staining For the confirmation of the lactic acid bacteria gram staining was performed initially for the known organisms.

Sugar Fermentation Test Sugar fermentation is one of the important biochemical interactions between the organisms and nutritional contents. This test will gives you the clear idea about the fermentation of sugars and release of acid and gas in the broth medium. The culture was incorporated with various sugars in peptone water to that durhams tube was inserted inversely to see the any gas productions. Five sugars were been used here to analyze the organism activity towards various sugars.

Enzymatic Reactions. Starch Hydrolysis Most likely the $\mathrm{LAB}$ will give a positive reactions to starch hydrolysis. So the culture has been tested for the starch hydrolysis for the confirmations of the lactic acid bacteria.

Catalase Test The culture was treated with hydrogen peroxide to see whether any effervescences are seen or not.

\section{In Vitro Assessment Of Lactic Acid Bacteria Against}

Klebsiela Pneumoniae., (Mariam et al., 2014)

As described in the introduction part the cell free supernatant of the lactobacillus were treated with the Klebsiella pneumoniae., in three different concentrations to see the inhibitory effect of the LAB. The culture of lactic acid bacteria was centrifuged at $3000 \mathrm{rpm} / \mathrm{min}$ for $10 \mathrm{mins}$. And the supernatant was collected without the addition of pellet. And the supernatant was further filtered through what man No.1 filter paper for the successful filtration of the lactic acid bacteria. This collected supernatant was checked for the purity of the filtration. To check the purity of the supernatant, the collected supernatant was plated on nutrient agar plates to check for the growth of lactic acid bacteria. As well as the culture also been plated for the comparison between supernatant and cultured plates. After checking the purity of the supernatant of LAB, it is further prepared in three different concentrations with the nutrient broth medium for the $5 \mathrm{ml}$ of final volume. The concentrations about $12.5 \%, 25 \%$, and $50 \%$ will be treated with the $K$. pneumoniae., The $5 \mathrm{ml}$ final volume nutrient broth was prepared by adding $12.5 \%, 25 \%$ and $50 \%$ of the supernatant in three different sterile test tubes. One tube kept as a control without adding the supernatant $(5 \mathrm{ml}$ nutrient broth). And the readily prepared Klebsiella pneumoniae, broth was inoculated about $1 \mu \mathrm{l}$ in each test tubes. And the tubes were incubated at $37^{\circ} \mathrm{C}$ for 24 hours. After the incubation period, to know the growth rate of the Klebsiella pneumoniae., in treated and untreated tubes were measured the turbidity of both the tubes by using optical density in UV- spectrophotometer by the wavelength about $600 \mathrm{~nm}$.

\section{RESULTS}

\section{> Isolation and Identification of Klebsiella pneumoniae.,}

In the preliminary culture technique, the growth was appeared in various morphological and cultural characteristics in the nutrient agar plates. And the colony which has a Mucoid and opaque appearance was selected and tested for further studies. As well as other colonies also performed for further tests.

Gram staining was performed for various colonies selected from the nutrient agar plates. The mucoid colonies were observed as a gram negative, rod shaped, singly appearance, and very short bacteria under the oil immersion with the $100 \mathrm{X}$ magnification. The particular isolate was selected and sub cultured.(Fig-01)

Capsule staining gave a positive result for the selected isolated colonies. The colony appeared as clear zone around the rod shaped bacteria because of the presence of polysaccharides in it. Such polysaccharides never been stained with dyes.

One of the unique characteristics of K.pneumoniae., was it is non motile while most of the coli form bacteria are motile. And both the hanging drop method and SIM agar method gave negative results for the selected isolates.(Fig03)

And the more preferable test used to differentiate between the genus of coli form bacteria and the enteric bacteria. The selected isolate gave negative results to indole and methyl red tests. As the result of indole test didn't gave red colour ring when the reagent was added. 
And methyl red reagent didn't produce red colour change in throughout the medium when added into the broth medium. And it gave positive results for the voges proskauer and citrate utilization tests. Red colour changes was appeared when the reagent was added to the broth medium. And citrate tubes turned into Prussian blue colour from the actual green colour. (Fig02)

Enzymatic studies also one of the distinguishable one from wide range of bacterial community. Catalase gave positive reactions for the isolates where the oxidase giving negative results. Identification of the selected isolates were partially done with the above test results and further confirmation done with the MALDI-TOF analysis. The report I got from the microbiological laboratory shows the selected isolate was identified as Klebsiella pneumoniae.,

The results were observed and tabulated. (Table-1)

\section{> Isolation and identification of lactic acid bacteria (LAB)}

The culturing of the dry powder of LAB was observed and the colony appearance of the LAB was seen as white and creamy appearances and also in pure form of culture. There is no growth in control plate too. Hence the growth of the LAB was confirmed partially and these colonies were further introduced in to various tests.

Gram staining has shown gram positive rod shaped bacteria under the $100 \mathrm{x}$ magnification in oil immersion.(Fig-04)

Sugar fermentation is one of the major test in the differentiating the gram positive bacteria at the genus level. Here All the sugars have been fermented and produced gas except arabinose sugar. Arabinose alone gave only acid not gas. More over all the lactic acid bacteria will ferment all the sugars but the difference will be happen only in the acid and gas production based on the strain variations.(Fig-05)
And another one important test that helps in differentiating the gram positive bacteria is that starch hydrolysis and catalase tests. Starch is the polysaccharides in which the amylase will react and dehydrolyse it and produce clear zone around the growth of the culture. The isolate also produced clear zone around the growth of the culture when flooded with the lugol's iodine solution (Fig06). And another one is catalase test it gave negative result for the culture grown.

Based on the all the above mentioned test results, the presence of lactic acid bacteria was confirmed. And the results were tabulated (Table-02)

\section{> In Vitro Assessment of Lactic Acid Bacteria Against Klebsiela Pneumoniae., \\ Researchers have been studied and revealed that the lactic acid bacteria highly possess the antimicrobial activity on various urogenital microbes, enteric pathogens, as well as several human and cattle pathogens. Such studies was the basis for this current work. The supernatant of lactic acid bacteria which consist of several organic acids and some metabolites in it. That was treated with one of the important human and cattle pathogen Klebsiella pneumoniae., with the three different concentrations. And this current study was successfully comes with the expected inhibitory effect to the $K$. pneumoniae., Based on the optical density I got, the graphical representation(Graph- 01) was made. When observing the graph, the peak which represents the growth of the $K$. pneumoniae., was very high in control and lesser in the proportions to the concentrations of the supernatant. Which indicates the suppress of the growth of the pathogen in the tubes treated with the supernatant. Here proved that the supernatant of LAB consist of effective antimicrobial activity in it. It should be further analyzed and identify that which the compound highly involved in this process.}

\section{* Tables and Figures}

\begin{tabular}{|c|c|r|c|}
\hline \multicolumn{2}{|c|}{ MORPHOLOGICAL CHARACTERISTICS } \\
\hline 1 & Nutrient agar medium & $\begin{array}{c}\text { Mucoid, Opaque } \\
\text { Pale yellow in colour. }\end{array}$ & RESULT \\
\hline S.NO & TEST NAME & OBSERVATIONS & Gram negative, bacilli \\
\hline 2 & Gram reaction & Pink coloured, rod shaped bacilli & Positive \\
\hline 3 & Capsule staining & Clear zone around the colonies & Negative \\
\hline
\end{tabular}




\begin{tabular}{|c|c|c|c|}
\hline \multicolumn{4}{|c|}{ BIOCHEMICAL TESTS } \\
\hline 5 & Indole & $\begin{array}{l}\text { No red colour ring was observed at the } \\
\text { top of the medium. }\end{array}$ & Negative \\
\hline 6 & Methyl red & $\begin{array}{l}\text { No change of red colour was observed } \\
\text { throughout the medium. }\end{array}$ & Negative \\
\hline 7 & Voges proskauer & $\begin{array}{l}\text { Red colour was observed throughout } \\
\text { the medium. }\end{array}$ & Positive \\
\hline 8 & Citrate utilization test & $\begin{array}{c}\text { Green colour was changed to Prussian } \\
\text { blue colour. }\end{array}$ & Positive \\
\hline \multicolumn{4}{|c|}{ ENZYMATIC REACTIONS } \\
\hline 9 & Catalase & Effervescences seen & Posititve \\
\hline 10 & Oxidase & No colour change was observed & Negative \\
\hline
\end{tabular}

Table 1:- Showing the results for the isolation and identification of Klebsiella pneumoniae.,

\begin{tabular}{|c|c|c|c|}
\hline \multicolumn{4}{|c|}{ MORPHOLOGICAL CHARACTERISTICS } \\
\hline 1 & Nutrient agar medium & $\begin{array}{l}\text { White coloured, raised, irregular } \\
\text { colony was appeared. }\end{array}$ & \\
\hline S.NO & TEST NAME & OBSERVATIONS & RESULT \\
\hline 2 & Gram reaction & Violet coloured, rod shaped bacilli & Gram positive, bacilli \\
\hline \multicolumn{4}{|c|}{ SUGAR FERMENTATION TESTS } \\
\hline 3 & Glucose & Acid / Gas & Positive \\
\hline 4 & Sucrose & Acid / Gas & Positive \\
\hline 5 & Maltose & Acid / Gas & Positive \\
\hline 6 & Lactose & Acid / Gas & Positive \\
\hline 7 & Arabinose & Acid & Positive \\
\hline \multicolumn{4}{|c|}{ ENZYMATIC REACTIONS } \\
\hline 8 & Catalase & No effervescences seen & Negative \\
\hline 9 & Starch hydrolysis & $\begin{array}{l}\text { Clear zone around the growth was } \\
\text { seen. }\end{array}$ & Positive \\
\hline
\end{tabular}

Table 2:- Showing the results for the isolation and identification of the Lactic acid bacteria. 


\begin{tabular}{|c|c|c|}
\hline S.NO & CONCENTRATIONS in \% & OD VALUE in 600nm \\
\hline 1 & 12.5 & 0.943 \\
\hline 2 & 25 & 0.920 \\
\hline 3 & 50 & 0.636 \\
\hline 4 & CONTROL & 1.854 \\
\hline
\end{tabular}

Table 3:- showing in vitro efficacy of the lactic acid bacteria against Klebsiella pneumoniae.,

* Graphical Representation of OD Values.

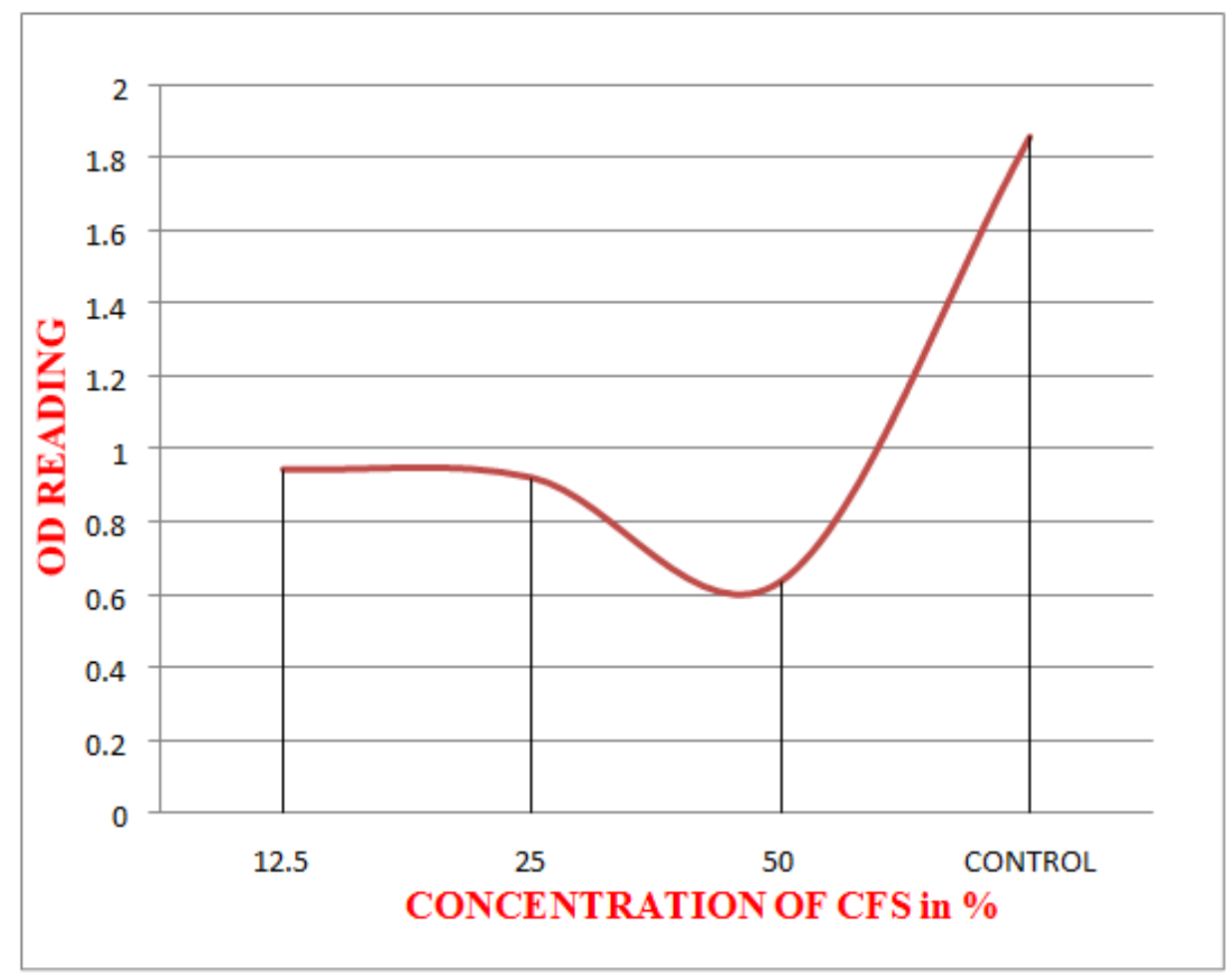

Graph 1

Figure showing the results for the identification of Klebsiella pneumoniae.,

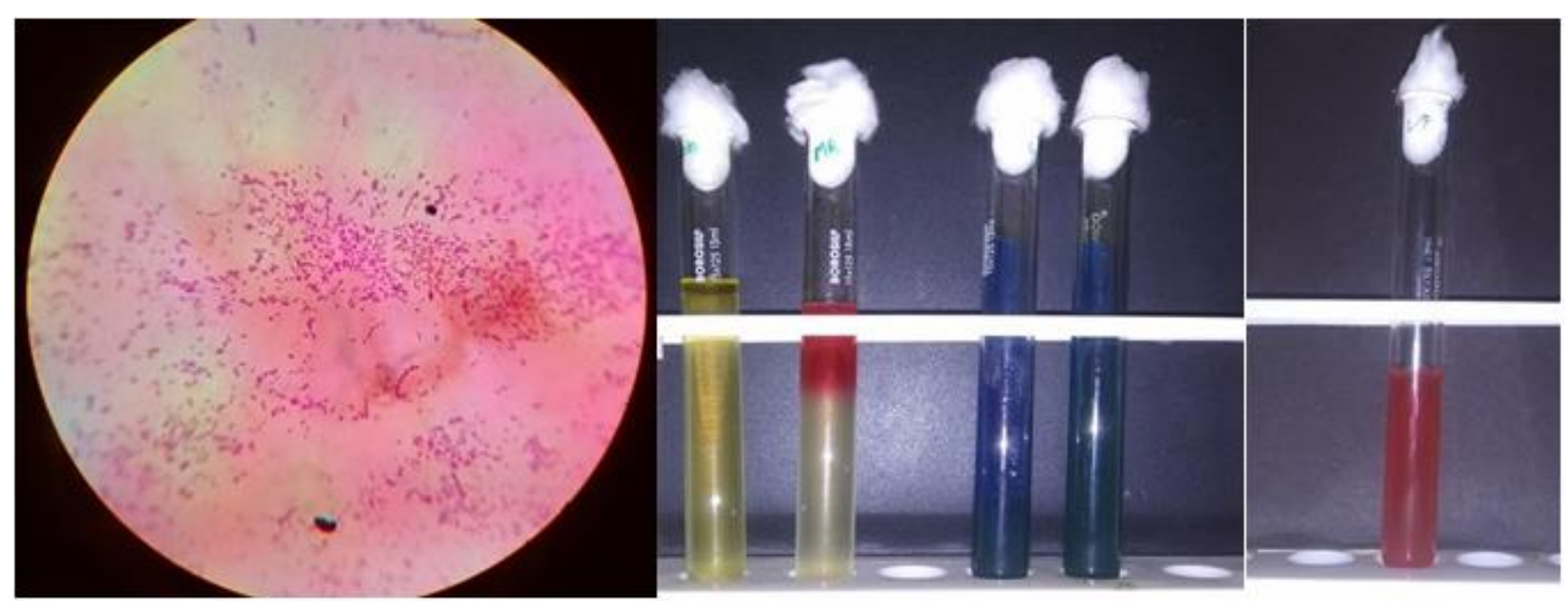

Fig 1:- Gram negative, bacilli

Fig 2:- Indole, Methyl red, Citrate utilization, Voges proskauer, 


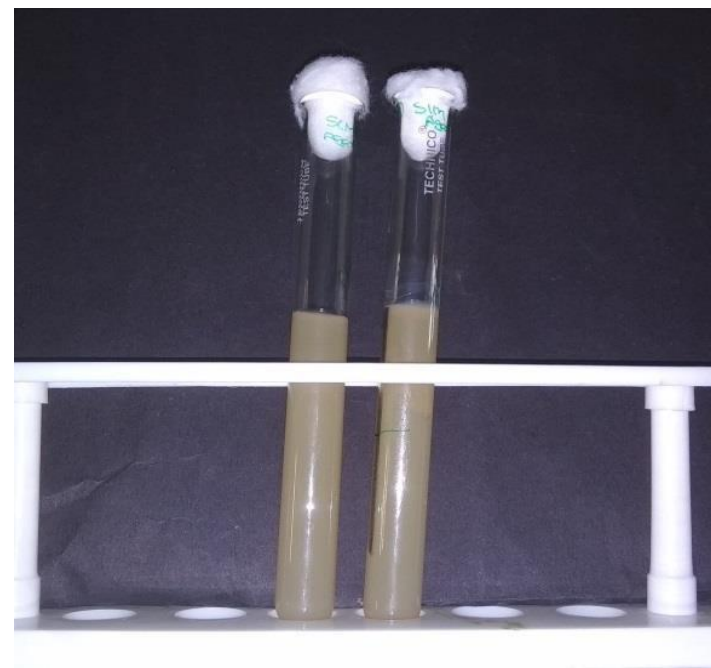

Fig 3:- Non Motile in Sim agar.

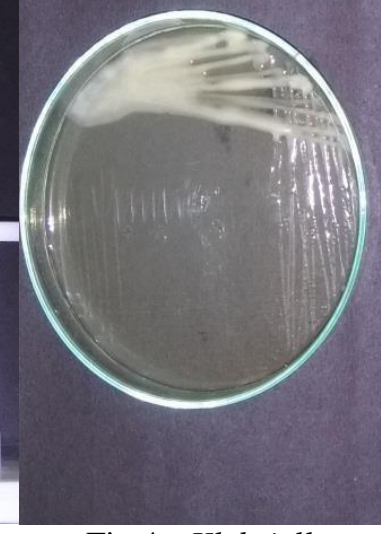

Fig 4:- Klebsiella growth on nutrient agar plate

Figures showing the results for the identification of Lactic acid bacteria.

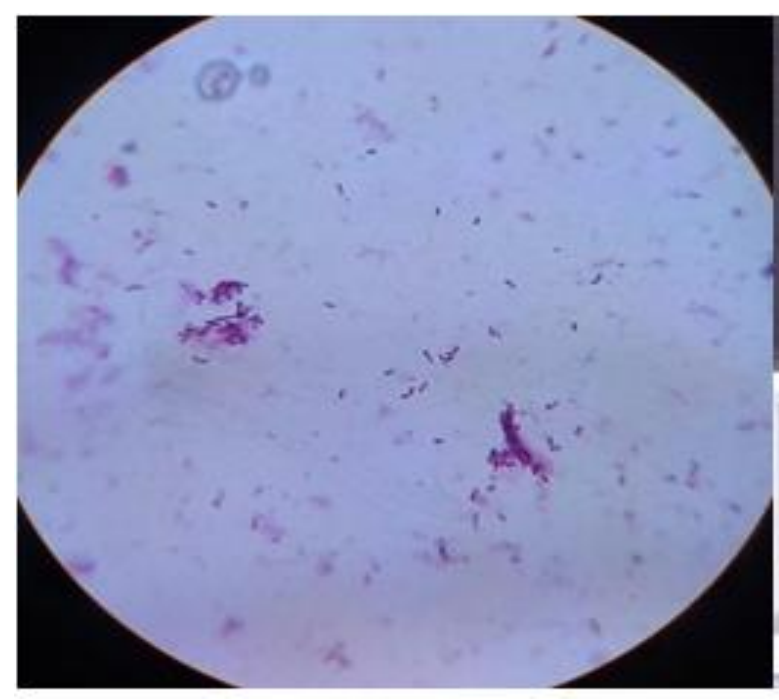

Fig 5:- Gram positive, bacilli
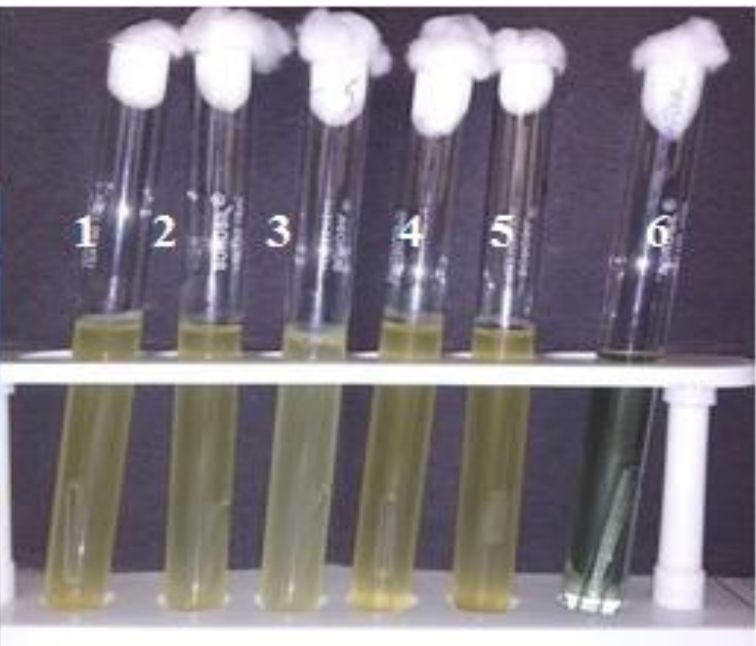

Fig 6:- Sugar fermentation. 1-Glucose 2-Sucrose 3-Arabinose 4-Lactose 5-Maltose 6-Control

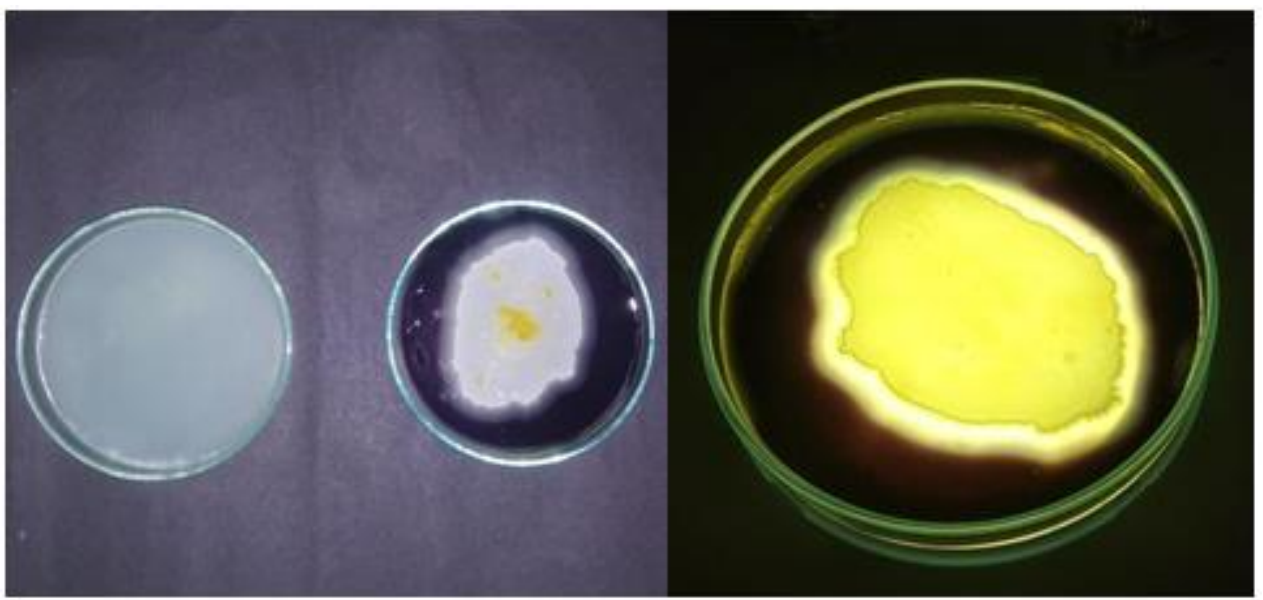

Fig 7:- Starch hydrolysis. (Positive)

Zone under light source 


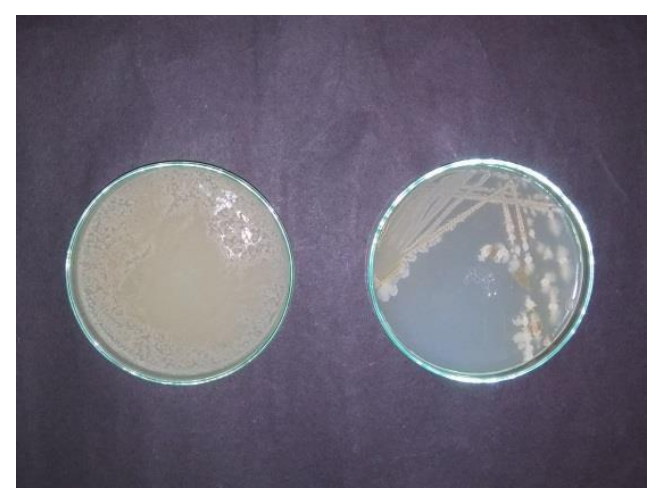

Fig 8:- Lactobacillus growth on Nutrient agar plate.

Figure showing the results for the in vitro efficacy of the lactic acid bacteria against Klebsiella pneumoniae.,

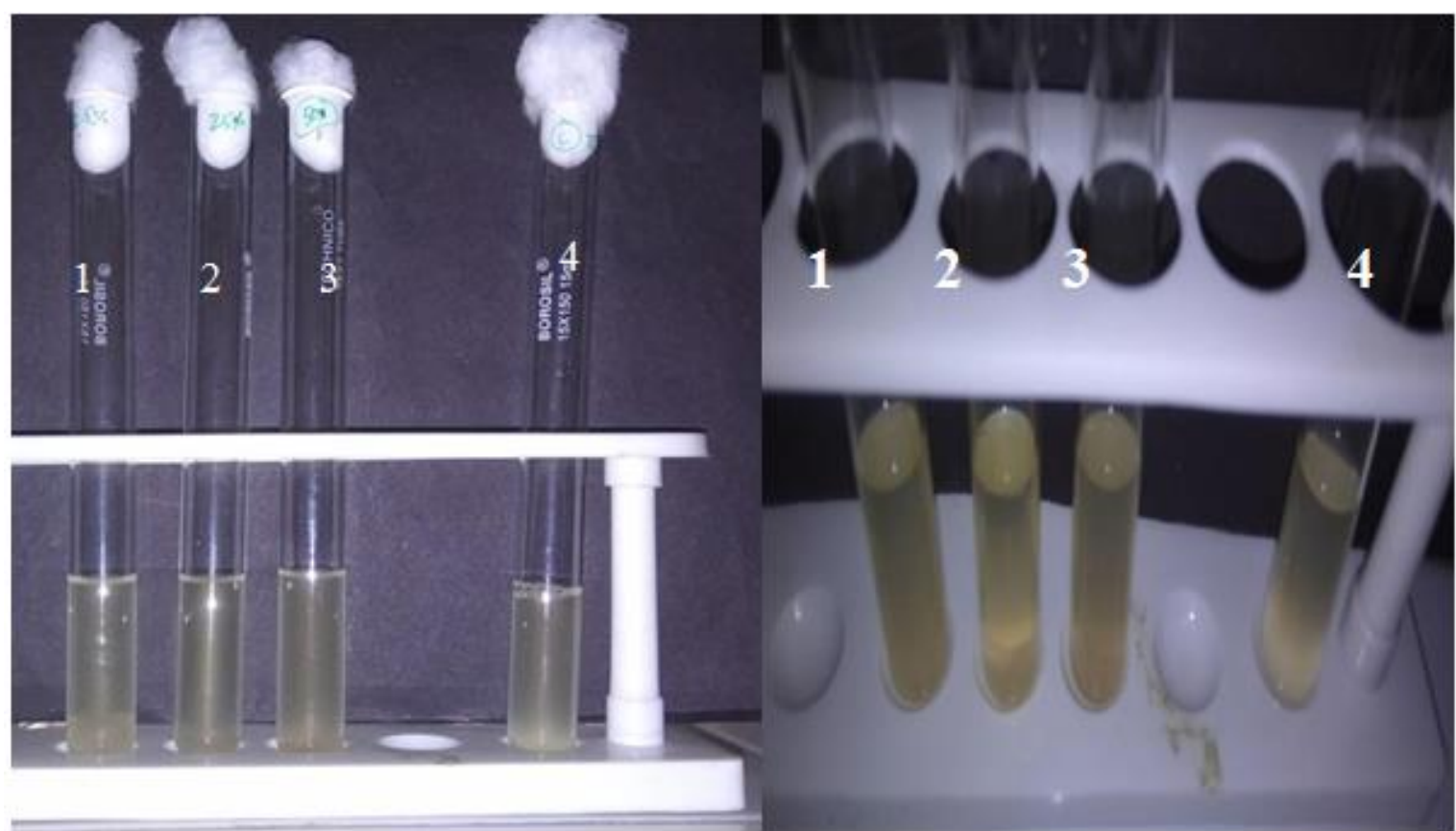

Fig 9:- Turbidity of both treated and untreated tubes. $1-12.5 \% \quad 2-25 \% \quad 3-50 \%$ 4- control

\section{DISCUSSION}

In recent years researchers has been found many therapeutics agents against for the human and cattle infecting pathogens found in human gut and farm house of cattle. Because of unhygienic and improper cleanings will harbor the highly pathogenic strains mainly in the farm house. Such one of the pathogenic strain Klebsiella pneumoniae, which causing the mammary glands in mammalian animals. In which the inflammation of the mammary glands will occur which leads to the death of an animals and also in humans when they having milk from cattles.

In this study covers the work which I have done to reveal the antimicrobial activity of lactic acid bacteria against one such important pathogenic strains of cattle as well as human also. The supernatant of the various lactic acid bacteria will inhibit the growth various pathogenic strains as said by the previous researchers. Based on that research work this study was successfully done. Here the supernatant of the lactic acid bacteria in three different concentrations were checked with the test strains such as Klebsiella pneumoniae., This study was carried to reveal the efficacy of the supernatant in inhibiting the growth of the test strains was done with the nutrient broth medium. Based on the turbidity in the treated and untreated tubes were measured by optical density by using spectrophotometer analysis. The results were came with our expectations. $50 \%$ supernatant was highly inhibiting the growth of the Klebsiella pneumoniae.,

This work shows the antibacterial activity of supernatant of LAB against Klebsiella pneumoniae., this supernatant has to be further analyzed for compound which is the sole responsible for the inhibiting activity of the lactic acid bacteria. As said by the researchers in previous the supernatant of the LAB highly possess with the organic acids and metabolites which could have this kind of activity in several pathogens. Such organic acids and metabolites are further separating and analyzing by the chromatographic methods and also HPLC method. 


\section{ACKNOWLEDGEMENT}

I would like to express my deepest appreciation to all those who provided me the possibility to complete this report. A special gratitude I give to Principal, Prof. Dr. V. RAJENDRAN, M.Sc., M.Phil., M.Tech., Ph.D., Dr. N.G.P. Arts and Science College(Autonomous), Coimbatore for his encouragement throughout the course. Apart from that I would like to express my deepest appreciation and gratitude to Dr. J. Renga ramanujam., M.Sc., M.Phil., PGDBI., Ph.D., NET, Head Department Of Microbiology, Dr. N.G.P. Arts and Science College(Autonomous), Coimbatore. And my sincere Appreciation, Thanks and Honour to my guide Mr. S. Senthil Prabhu., M.Phil., PGDCRDM., (Ph.D)., SET, Assistant professor(SG), Department Of Microbiology, Dr. N.G.P. Arts and Science College(Autonomous), Coimbatore. I take previlage to express my sincere thanks and gratitude to him for his guidance, constructive criticism and valuable suggestions. My deep and sincere gratefulness is due to all the staff members and laboratory assistant for their help and continue support for the successful completion of my work.

I am thankful to all the staffs, and my parents and my friends without their support and blessings this report would not have been possible.

\section{REFERENCES}

\section{Journal}

[1]. Abee T, Krockel L, Hill C: Bacteriocins: modes of action and potentials in food preservation and control of food poisoning. Int J Food Microbiol 1995, 28:169-185.

[2]. Caplicec E, Fitzgerald GF: Food fermentations: role of microorganisms in food production and preservation. Int J Food Microbiol 1999,50:131-149.

[3]. Natrajan N, Sheldon BW: Inhibition of Salmonella on poultry skin using protein- and polysaccharide-based films containing a nisin formulation. J Food Prot 2000, 63:1268- 1272 .

[4]. Abdullah SA and Osman MM. Isolation and identification of lactic acid bacteria from raw cow milk, white cheese and rob in Sudan. Pakistan Journal of Nutrition. 2010;9:1203-1206.

[5]. Harun-ur-Rashid, M, et al. Identification and characterization of dominant lactic acid bacteria isolated from traditional fermented milk Dahi in Bangladesh. World Journal of Microbiology and Biotechnology. 2007;23:125-133.

[6]. De Vuyst L, Leroy F: Bacteriocins from lactic acid bacteria: production, purification, and food applications. J Mol Microbiol Biotechnol 2007, 13:194-199.

[7]. Coeuret V., Vubernet S., Bernardeau M., Gueguen M. and VernouyJ. P. 2003. Isolation, characterization and identification of Lactobacilli focusing mainly on cheese and other dairy products. Lait, 83: 269-306.

[8]. Hoque M.Z.,Akter F.,Hossain M.K.,Rahman M.S.M.,Mbillah M. and ISLAM K.M.D.
[9]. 2010.Isolation, identification and analysis of probiotic properties of Lactobacillus Spp. from selective regional yogurts.World J. Dairy and Food Sci., 5(1): 39-46.

[10]. Patra, A.,Sil J. and DAS B. 2011.Isolation and characterization of dominant lactic acid bacteria from dahi at Medinipur and evaluation of their antimicrobial activity, Internet J. Food Safety, 157163.

[11]. Savadogo T.O.,Ouattara C.T.O.T.,Bassole I.H. and Traore, S.A. 2006. Bacteriocins and lactic acid bacteria. African J. Biotechnology, 5: 678-683.

[12]. Elizete D.F.R.P. and Carlos R. S. 2005.Biochemical characterization and identification of probiotic Lactobacillus for swine.B. CEPPA, Curitiba, 23: 299 310.

[13]. AL-Kafaji ， Z. M. 1992 . Influence of various condation on Inhibitory effect of intestinal Lactobacillus against intestinal bacteria causes diarrhea. Iraqi J. of Science,3(1):18-26.

[14]. Reid, G. and Burton, J. 2002.Use of Lactobacillus to prevent infection by pathogenic bacteria.Microbes and infection 4: 319-324.

[15]. Arena MP, Silvain A, Normanno G, Grieco F, Drider D, Spano G, Fiocco D. Use of Lactobacillus plantarum strains as a bio-control strategy against food-borne pathogenic microorganisms. Front Microbiol. 2016;7:464.

[16]. Arques JL, Rodriguez E, Langa S, Landete JM, Medina M. Antimicrobial activity of lactic acid bacteria in dairy products and gut: effect on pathogens. BioMed Res Int. 2015

[17]. Diba FS, Hossain KM, Azim MA, Hoque M. Isolation, characterization and determination of antimicrobial properties of lactic acid bacteria from human milk. Jordan J Biol Sci. 2013;6:111-116.

[18]. Reis JA, Paula AT, Casarotti SN, Penna AL. Lactic acid bacteria antimicrobial compounds: characteristics and applications. Food Eng Rev. 2012;4:124-140.

[19]. Khiralla GM, Mohamad EAH, Farag AG, et al. Antibiofilm effect of Lactobacillus pentosus and Lactobacillus plantarumcell-free supernatants against some bacterial pathogens. J Biotech Res 2015; 6: 8695.

[20]. Ait Ouali F, Al Kassaa I, Cudennec B, et al. Identification of lactobacilli with inhibitory effect on biofilm formation by pathogenic bacteria on stainless steel surfaces. Int J Food Microbiol 2014; 191: 116124.

[21]. Gomez NC, Ramiro JM, Quecan BX, et al. Use of potential probiotic lactic acid bacteria (lab) biofilms for the control of Listeria monocytogenes, Salmonella typhimurium, and Escherichia coli O157:H7 biofilms formation. Front Microbiol 2016; 7: 863.

[22]. Aminnezhad S, Kasra-Kermanshahi R. Antibiofilm activity of cell-free supernatant from Lactobacillus casei in Pseudomonas aeruginosa. Feyz 2014; 18(1): 30-37. 
[23]. Mirnejad R, Vahdati AR, Rashidiani J, et al. The antimicrobial effect of lactobacillus casei culture supernatant against multiple drug resistant clinical isolates of Shigella sonnei and Shigella flexneri in vitro. Iran Red Crescent Med J 2013; 15(2): 122-126.

[24]. Englund M. Lactobacillus - a review of the beneficial effects to human health. Forslarskolanii, Lund. 1992, $1-16$.

[25]. Schillinger U, Lucke FK , Appl. Environ. Microbiol., 1989 , 55, 1901-1906.

[26]. Das JK, Mishra D, Ray P, Tripathy P, Beuria TK, Singh N, Suar M. 2013. In vitro evaluation of antiinfective activity of a Lactobacillus plantarum strain against Salmonella enterica serovar Enteritidis. Gut Pathog. 5:1-11.

[27]. Ariffin, H.; Navaratnam, P.; Mohamed, M.; Arasu, A.; Abdullah, W.A.; Lee, C.L.; Peng, L.H. Ceftazidimeresistant Klebsiella pneumoniae bloodstream infection in children with febrile neutropenia. Int. J. Infect. Dis. 2000, 4, 21-25. [CrossRef]

[28]. Hennequin, C.; Forestier, C. Influence of capsule and extended-spectrum beta-lactamases encoding plasmids upon Klebsiella pneumoniae adhesion. Res. Microbiol. 2007, 158, 339-347. [CrossRef]

[29]. Jarvis, W.R.; Munn, V.P.; Highsmith, A.K.; Culver, D.H.; Hughes, J.M. The epidemiology of nosocomial infections caused by Klebsiella pneumoniae. Infect. Control 1985, 6, 68-74. [CrossRef] Sensors 2017, 17, 140612 of 13

[30]. De Champs, C.; Sauvant, M.; Chanal, C.; Sirot, D.; Gazuy, N.; Malhuret, R.; Baguet, J.; Sirot, J. Prospective survey of colonization and infection caused by expanded-spectrum-betalactamaseproducing members of the family Enterobacteriaceae in an intensive care unit. J. Clin. Microbiol. 1989, 27, 2887-2890.

[31]. Podschun, R.; Ullmann, U. Klebsiella spp. as nosocomial pathogens: Epidemiology, taxonomy, typing methods, and pathogenicity factors. Clin. Microbiol. Rev. 1998, 11, 589-603. 